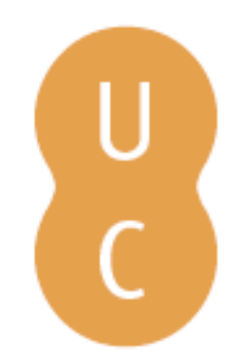

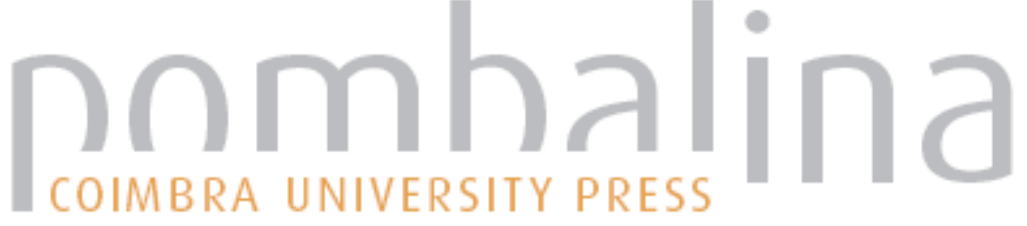

\section{O fantástico e a poética da verdade n'Os Lusíadas}
Autor(es):
Macedo, Helder
Publicado por: Imprensa da Universidade de Coimbra
URL persistente:
URI:http://hdl.handle.net/10316.2/30740
DOI:
DOl:http://dx.doi.org/10.14195/978-989-26-0569-2_3

Accessed : $\quad$ 26-Apr-2023 11:30:09

A navegação consulta e descarregamento dos títulos inseridos nas Bibliotecas Digitais UC Digitalis, UC Pombalina e UC Impactum, pressupõem a aceitação plena e sem reservas dos Termos e Condições de Uso destas Bibliotecas Digitais, disponíveis em https://digitalis.uc.pt/pt-pt/termos.

Conforme exposto nos referidos Termos e Condições de Uso, o descarregamento de títulos de acesso restrito requer uma licença válida de autorização devendo o utilizador aceder ao(s) documento(s) a partir de um endereço de IP da instituição detentora da supramencionada licença.

Ao utilizador é apenas permitido o descarregamento para uso pessoal, pelo que o emprego do(s) título(s) descarregado(s) para outro fim, designadamente comercial, carece de autorização do respetivo autor ou editor da obra.

Na medida em que todas as obras da UC Digitalis se encontram protegidas pelo Código do Direito de Autor e Direitos Conexos e demais legislação aplicável, toda a cópia, parcial ou total, deste documento, nos casos em que é legalmente admitida, deverá conter ou fazer-se acompanhar por este aviso.

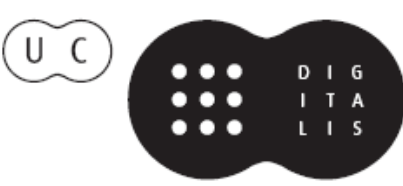




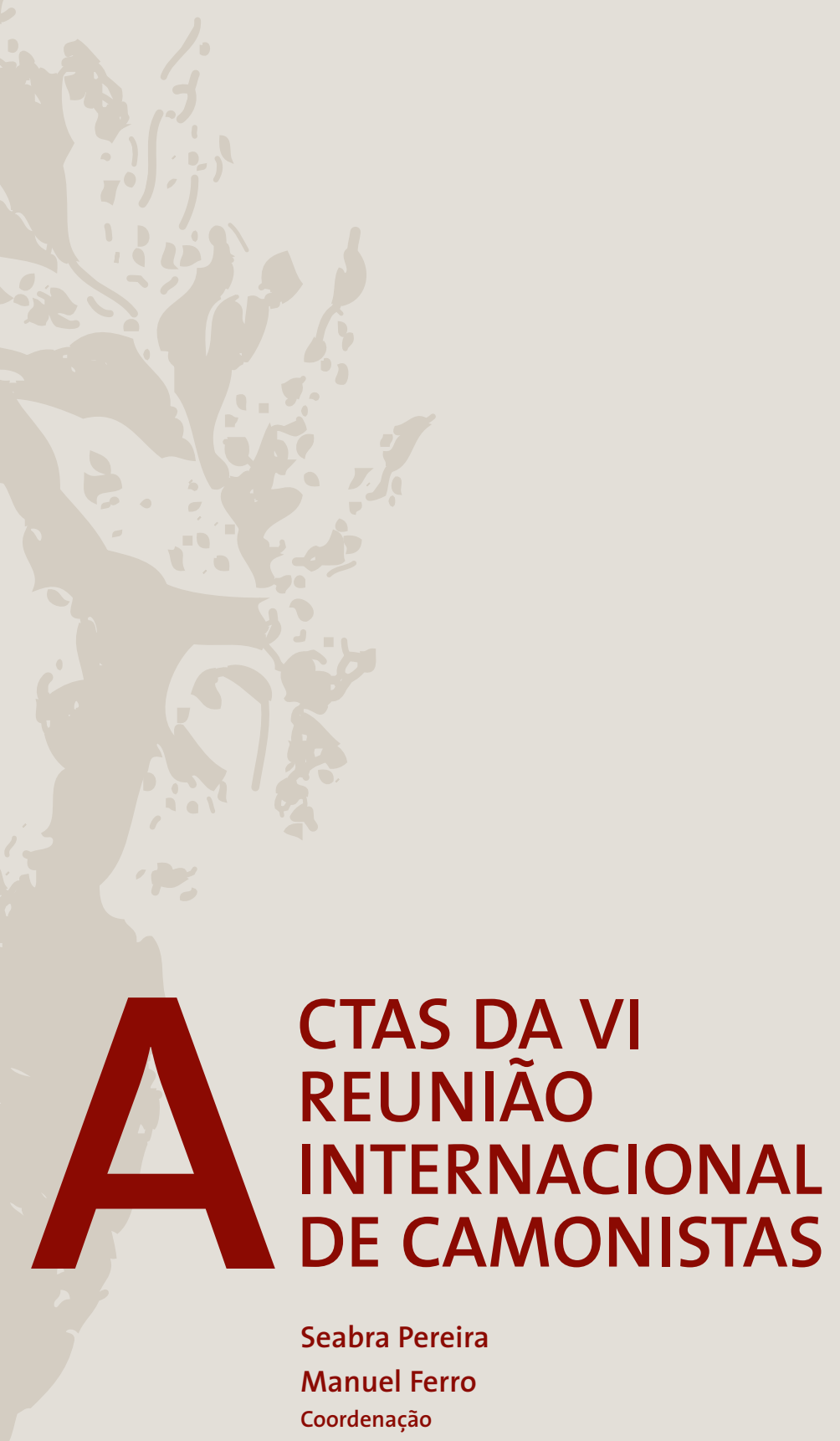


Helder Macedo

Universidade de Londres - King's College

\section{O FANTÁSTICO E A POÉTICA DA VERDADE N'OS LUSÍADAS}

O período cultural que, em termos amplos, pode ser designado como o Renascimento português contém uma forte tradição de sensata e quase céptica racionalidade que se opõe às nebulosidades pós-sebastianicamente associadas à identidade nacional. Fernão Lopes transforma a profecia numa metáfora laica - «como quem jogueta $e$ per comparaçom» - para caracterizar acontecimentos recentes, e bem conhecidos, como e se tivessem constituído o advento da Sétima Idade: semanticamente, isto é o oposto da genuína profecia que, por definição, aponta para um futuro desconhecido. D. Duarte analisa «as desvairadas maneiras que se dá fé às profecias, visóes, sonhos, (...) estrolazia, nigromancia, geomancia e outras semelhantes ciências, artes, sperimentos e sotilezas», para concluir que "o mais seguro caminho é nom curar de todo esto». Gil Vicente satiriza essas mesmas falsas crenças e condena aqueles que delas se serviam para proveito próprio. A poesia de Sá de Miranda é uma frontal afirmação da integridade do "entendimento" contra as obscuras irracionalidades manifestadas num alienador "encantamento». Mesmo Bernardim Ribeiro, no seu ambíguo universo de sombras materializadas, diz que os sonhos não vêm «senão do que homem traz na fantasia» e vincula o desencadear da prefiguração profética à previsibilidade objectiva das acçóes humanas com base nos precedentes estabelecidos por acçōes semelhantes. E, já em pleno sebastianismo, D. Francisco Manuel de Melo procurou neutralizar as presunçóes transmundanas do misticismo profético ao estabelecer uma subtil correspondência entre a exegese cabalística e a retórica tradicional.

A obra de Luís de Camóes insere-se nesta persistente tradição e, como procurarei mostrar com especial referência a Os Lusíadas, a racionalidade inerente à sua visão do mundo é tanto mais profunda quanto lhe permite fazer um uso poético do irracional como parte de uma estratégia literária de verosimilhança. Numa obra que, logo desde o primeiro verso, remete para a intertextualidade, Camóes colocou o histórico e o mítico, o factual e o imaginário, os deuses e os homens ao mesmo nível de representação estética. No centro dessa obra, no entanto, está o próprio poeta que a escreveu e que explicitamente se assume náo apenas como o seu autor mas também como o seu personagem exemplar, por virtude de em si ter reunido as verdades da experiência vivida, os ensinamentos da cultura recebida, e a capacidade de as transformar numa nova significação totalizante. 
As viagens marítimas iniciadas pelos portugueses trouxeram para a cultura europeia a problemática do novo e do diferente sem que o pensamento filosófico e a imaginação poética tivessem ainda construído a linguagem necessária para lhes dar significaçáo. Camóes foi o poeta do novo e do diferente com a linguagem do antigo e do semelhante. Poeta de "honesto estudo», a originalidade do seu génio expressa-se sobretudo através de sucessivos deslocamentos de ênfase dentro das formas e géneros existentes; cidadão com "a vida pelo mundo em pedaços repartida», o projecto implícito na sua obra é a recuperação do equilíbrio humanista entre a fé e a experiência, o pensamento e a acção, o espírito e a matéria, o apetite e a razáo, as armas e as letras, numa nova ordem que já não cabia na harmonia quebrada de um mundo em desconcerto. Num soneto onde a própria fé se manifesta como um paradoxo do conhecimento, Camóes dá notícia de um mundo onde "cousas hái que passam sem ser cridas / E cousas cridas há sem ser passadas", onde "doutos varôes darão razóes subidas / Mas são experiências mais provadas / E por isso é milhor ter muito visto». Noutro soneto, traz para o espaço semântico da representaçáo literária o relativismo da sua recepção por parte dos diversos leitores cujas experiências determinarão, como lhes declara, que «segundo o amor tiverdes / Tereis o entendimento de meus versos».

E noutro ainda, quando escreve "errei todo o discurso de meus anos», persiste em atribuir ao seu percurso no mundo o valor de uma errância transformada em significação, mesmo se num projecto finalmente malogrado no plano individual. N'Os Lusíadas, Camôes faz uma equivalente transposição da errância da História para a significação do discurso poético, reiterando também, de diversos modos e em diversas vozes, a fundamental afirmação com que termina uma das suas cançôes: "Nem eu delicadezas vou cantando, (...) mas explicando puras verdades já por mim passadas».

Logo nas primeiras estrofes d'Os Lusíadas, Camôes afirma a superioridade da sua epopeia por ser baseada na verdade da História e não, como as das "musas estranhas», nas falsidades do Mito. No entanto, o poema prontamente passa a incluir o mítico, o fantástico, o profético, o onírico, todo um imaginário fabuloso representado na transposição das acções dos homens para as maquinaçôes das divindades pagãs que vão presidir aos seus destinos e conferir-lhes significação exemplar. Mas Camôes pode fazêlo sem contradição, porque esses invólucros de crenças esvaziadas foram transformados nos "nomes" poéticos de veracidades factuais, nas metáforas da História através das quais as obscuras intençóes divinas se poderiam tornar racionalmente inteligíveis. Por isso os deuses, cumprida a sua função retórica, podem auto-eliminar-se do poema, dizendo: "Só para fazer versos deleitosos / Servimos; e, se mais o trato humano / Nos pode dar, é só que o nome nosso / Nestas estrelas pôs o engenho vosso». O que o poeta está a dizer não é apenas que os nomes dos deuses pagãos serviram para dar nomes aos astros, como habitualmente se entende. Diz bem mais do que isso: que esses nomes que lhe serviram para fazer os «versos deleitosos» do seu próprio poema são os veículos fictícios (diríamos hoje os «significantes») que lhe permitiram dirigir o engenho humano para as cósmicas verdades que constituem o universo real. Na mesma estrofe, os metafóricos deuses da significação poética também afirmam que vão deixar o seu lugar ao "vero Deus». No entanto, duas estrofes antes, o poeta já tinha declarado: "Mas o que é Deus ninguém o entende, / Que a tanto o engenho humano não se estende». Ao colocar o «saber divino» - "que é sem princípio e meta limitada» - fora do finito mundo onde se situa o humano entendimento, Camóes não se teria afastado das concepçóes 
filosóficas aceites pela ortodoxia cristã e católica do seu tempo. Mas utilizou-as para colocar Deus fora do espaço semântico de um discurso poético que visa dar uma significação náo teológica ao mundo inteligível e a destinos humanos com princípio e meta limitada. Essa significação é aquela que o discurso poético conseguir conferir à transitória existência humana.

Complementarmente, numa das suas mais veementes intervençóes pessoais no poema, Camóes torna claro que nem "o nosso Gama nem quem na estirpe seu se chama» as musas tem por tão amigas "que deixassem / As telas de ouro fino e que o cantassem». Esta passagem vem na imediata sequência do discurso de Vasco da Gama ao rei de Melinde e, ao servir para caracterizar esse discurso como uma expressão dramática da voz do próprio poeta, contém também uma sugestão mais profunda e mais radical: Camões é o "autor" de Vasco da Gama, como se ele, e por extensão as outras personagens históricas d'Os Lusiadas, não tivessem outra existência além daquela que o texto poético lhes está a conferir. Deuses fabulosos e heróis históricos são assim igualmente instituídos como significantes de um texto poético que, em última análise, remete ao seu autor e se define como auto-referencial.

A qualidade auto-referencial do poema já havia aliás ficado implícita na dedicatória a D. Sebastiấo, quando Camóes o exorta a que, para renovar a "memória» e as "obras valerosas» dos antepassados, torne seus os versos através dos quais lhe veio representar a História de que é parte e necessário continuador:

"Mas enquanto este tempo passa lento

De regerdes os povos que o desejam,

Dai vós favor ao novo atrevimento,

Para que estes meus versos vossos sejam."

Até o jovem rei ter dado nova matéria a «nunca ouvido canto», a celebração do passado só pode ser a crítica do presente e o modelo de futuro. Tethys e as ninfas marinhas «casaram-se» com os "heróis esclarecidos» na Ilha de Vénus; mas Tethys não pode mais do que ter "o dote aparelhado» para D. Sebastiáo. A épica camoniana situa-se no hiato da História entre o passado celebrado e o futuro desejado: simultaneamente define um tempo esvaziado, que "passa lento», e vem preenchê-lo com o "novo atrevimento» que é o próprio poema, desse modo investido com uma qualidade equivalente à desse outro 'atrevimento' (como lhe chamam Baco e Adamastor), que foi a aventura histórica apenas nele celebrada. Mas é apenas no "mar irado" da representação literária que o tempo cronológico pode ser obliterado na sua significação, permitindo não só que o presente veja o passado, mas também que o passado veja e invoque um futuro que lhe desse continuidade:

"E vereis ir cortando o salso argento

Os vossos argonautas, por que vejam

Que são vistos de vós no mar irado;

E costumai-vos já a ser invocado."

Camóes transpôs assim a viagem heróica do passado para a viagem de heróicas incertezas que é o discurso poético em que a celebra. E o progresso dessa sua outra 
viagem no «mar irado» da poesia - o «novo atrevimento» - também vai sendo registado em contraponto com o progresso da viagem celebrada no poema, até que, ainda mais acentuando o seu carácter auto-referencial, acaba mesmo por se substituir ao seu valor semântico. Tendo já caracterizado Vasco da Gama como um seu significante poético, Camóes vai também intervir na fala do irmão, Paulo da Gama, para declarar que o poema em que celebra a viagem histórica de que eles são protagonistas também o traz a si em "alto mar» e com "vento táo contrário", que teme que o seu "fraco batel se alague cedo». O valor metafórico desta reiterada correspondência semântica entre a viagem celebrada e a sua representação no "mar irado» da poesia adquire uma amplificada conotaçáo de factualidade biográfica na referência que o poeta logo faz aos perigos e trabalhos que passou enquanto a Fortuna o traz peregrinando: «Agora o mar, agora experimentando / Os perigos Mavórcios inumanos /... / Nua máo sempre a espada e noutra a pena». A equivalência entre as suas experiências de Armas e as dos heróis que celebra no poema é manifesta. Mas a essas Camóes acrescentou os seus feitos nas Letras, ou seja, a sua capacidade de lhes conferir significação nesse mesmo poema em que também se inclui.

É neste contexto que faz uma primeira referência ao naufrágio em que quase perdeu a vida e o poema. A correspondência metafórica entre o discurso poético e a viagem literalizou-se numa nova correspondência ameaçadora entre o poema - o «fraco batel» em "alto mar» e "com vento táo contrário» que teme que se «alague cedo» - e o naufrágio real que sofreu. Essa correspondência vai ser retomada quando de novo se refere ao naufrágio, na fictícia voz profética que conta aos navegantes as coisas futuras na Ilha do Amor:

"Este receberá, plácido e brando

No seu regaço o Canto que molhado

Vem do naufrágio triste e miserando,

Dos porcelosos baxos escapando,

Das fomes, dos perigos grandes, quando

Será o injusto mando executado

Naquele cuja lira sonorosa

Será mais afamada que ditosa."

A subtil sintaxe desta estrofe torna metonimicamente intermutáveis o poeta e o poema, "o Canto que molhado vem do naufrágio" e "aquele cuja Lira sonorosa será mais afamada que ditosa», simultaneamente integrando na significação do poema o naufrágio que ameaçou destruí-lo, e os "profetizados» sofrimentos do seu autor. Essa "profecia» é situada entre várias outras - sobre feitos de armas, acções virtuosas, lugares remotos, povos estranhos - que são feitas aos heróis do passado para lhes dar a visão do futuro e que, como parte da estratégia literária do poema, servem para trazer a narrativa histórica até ao tempo presente da sua escrita. Enquanto profecias são, portanto, fictícias. Mas, como parte dessa mesma estratégia literária, são como profecias que tivessem sido confirmadas pela História no plano do mundo tornado inteligível pela representação poética. Assim, a ameaça que paira sobre aquele «cuja Lira sonorosa será mais afamada que ditosa» fica igualmente a pairar sobre a sua matéria poética - a nação celebrada no «Canto que molhado vem do naufrágio». Daí o elemento de insidiosa dúvida, tornada 
em crescente desespero, nas intervençóes pessoais de Camóes quando o poema se aproxima do fim. Numa delas, depois de justapor a sua própria mortalidade com a imortalidade que deseja dar à pátria, pede à "grão rainha das Musas» que lhe restaure o gosto de escrever, que está perdendo, para poder completar o "trabalho extremo» que vem realizando: "Mas tu me dá que cumpra (...) co que quero à Nação minha». $\mathrm{Na}$ seguinte, desiste finalmente de continuar a cantar para "gente surda e endurecida".

O mesmo silêncio da morte ameaça o poeta, o poema e a "gente surda» em que a nação se transformara. É portanto com este pesado sentido de mortalidade que Camôes se dirige de novo a D. Sebastiâo, a quem havia pedido que desse "favor ao novo atrevimento", tornando seus os versos com que viera preencher o esvaziado "tempo lento" no hiato entre o passado e o futuro. E vai concluir o poema com a ambígua formulação retórica de uma profecia cujo valor de prefiguração é condicional à sua recepção por parte daquele a quem o dirigiu segundo o amor tiver. $\mathrm{O}$ que a "pressaga mente vaticina» é uma tautologia que remete à compreensão da veracidade do próprio texto que a formulou, mas que por isso mesmo permitiria ao poeta recuperar a sua "já estimada e leda Musa».

Camóes dessacralizou a profecia quando a transpôs do plano do «saber divino» para o finito mundo da linguagem, onde se situa o humano entendimento. Foi aí também que igualmente situou os Deuses míticos, e os heróis históricos. Ao fazê-lo, instituiu o texto literário enquanto tal como o veículo dum outro tipo de verdade que lhe permite um trânsito livre entre o real e o fantástico, a História e o Mito, o eu e os outros. E mais ainda acentua que de um texto literário se trata através das persistentes relaçóes intertextuais que, desde o primeiro verso, vai estabelecendo com outras obras de outros autores, e das articulaçóes semânticas que vai fazendo com outros géneros poéticos. Assim, por exemplo, a Vénus camoniana é simultaneamente referenciada à Eneida e ao epicurismo pastoril renascentista, que nela representava as três vias capazes de levar o homem universal à verdadeira felicidade, combinando sabedoria, poder e prazer, ou seja, n’Os Lusíadas, a aliança de Vénus com Júpiter, com Marte e com Cupido; a caracterização do Rei-Menino, D. Sebastião, deve tanto às expectativas milenárias associadas às circunstâncias históricas do seu nascimento quanto ao puer virgiliano da Écloga Profética; a fala do Velho do Restelo transpóe versos de Ovídio sobre o contraste entre a dura Idade do Ferro e a pré-lapsária Idade do Ouro; a metamorfose de Adamastor, o Polifemo camoniano, deve tanto à tradiçáo pastoril quanto à épica de Homero, mas o Gigante Amoroso também não destoaria na Comedia de Dante. Os diversos géneros, obras e autores referenciados no poema, tal como as suas personagens históricas e míticas, também servem a Camôes como significantes poéticos do humano entendimento. São a linguagem do antigo e do semelhante usada para significar as experiências do novo e do diferente.

Mesmo os dois grandes momentos mágicos do poema - as metamorfoses complementares e antitéticas de Adamastor numa rocha estéril e de Vénus numa ilha fértil - podem ser entendidos como tendo correspondências factuais em experiências vividas. Ao nível da tipologia das percepçóes, o encontro dos navegantes com Adamastor corresponde a uma alucinação, e o visionamento da Ilha de Vénus a uma miragem. E ambas surgem na sequência de uma realística preparação psicológica.

A aparição de Adamastor culmina e funde numa só imagem ameaçadora a descrição de tais misteriosas «novidades» naturais como o «lume vivo» do fogo de santelmo, a «roxa 
sanguessuga» da tromba marítima, e a narrativa de um perigoso encontro com um "selvagem mais que o bruto Polifemo" com quem nenhuma comunicação é possível já que "nem ele entende a nós, nem nós a ele». E a Ilha de Vénus surge no horizonte quando, já de regresso à pátria, os lassos marinheiros desejam prover-se de «água fria para a longa viagem prolongada». Ao nível da efabulação poética, Vénus - ou Afrodite, a nascida das ondas - materializou essa expectativa de água fria numa ilha florescente que os marinheiros primeiro não vêem porque não existe, mas que vai seguindo a sua rota até que, quando um deles a visualiza, fica de repente parada como se sempre ali tivesse estado para que cada um deles nela pudesse executar todos os seus desejos. Mas ambas as ilusôes dos sentidos também correspondem a experiências plausíveis e a problemas reais da navegação marítima. Adamastor deriva, em parte, da existência observada de um grande cabo rochoso no fundo do continente africano, dos medos populares de que ali acabasse o mundo, e da experiência vivida pelo próprio Camóes de uma tempestade que na sua elegia autobiográfica já descrevera dizendo que «em serras todo o mar se convertia»; e a Ilha de Vénus também em parte reflecte o simples facto de os instrumentos do tempo só permitirem que se estabelecessem rotas segundo a Latitude. As inevitáveis margens de erro tornavam virtualmente impossível determinar o rumo para pequenas massas de terra, ou mesmo reencontrá-las depois de registadas nos mapas. Por isso muitos mapas registam ilhas que nunca mais foram encontradas, com uma legenda acrescentada debaixo do nome dizendo: «imaginária». Não foi com inocência que Thomas More situou o imaginário «não lugar» da Utopia numa tal ilha, e que atribuiu o seu inverificável encontro a um pioneiro português. $\mathrm{Ou}$, menos ainda, que Camóes transformasse uma hipotética ilha encontrada pelos pioneiros portugueses numa ilha da imaginação que estivesse a aguardar ser de novo encontrada pelo jovem rei a quem dedicou o seu poema. A Ilha do Amor é, em suma, uma representação poética do real situada no espaço ambíguo entre as "cousas que passam sem ser cridas» e as "cousas cridas que há sem ser passadas» - na sucinta formulação camoniana do soneto a Cristo.

Nesse soneto Camôes também diz que «doutos varôes darão razóes subidas / Mas são experiências mais provadas / E por isso é milhor ter muito visto". E diz qualquer coisa de semelhante no contexto do longo discurso de Vasco da Gama ao rei de Melinde, onde igualmente sugere que a verdade dos segredos escondidos pode residir mais na experiência da aparência das coisas do que nas especulaçóes sobre a sua transcendência. E foi assim que, provavelmente antecipando o que também iria dizer na Canção onde declara que o seu propósito não é cantar «delicadezas» mas explicar "puras verdades», Camóes pode utilizar a voz fictícia de Gama, o herói sem Musas, para definir o que é porventura a essência da sua própria perspectiva poética - «e tudo sem mentir, puras verdades». Mas essas "puras verdades» são o artifício do texto literário, a poética da verdade. 